\title{
Changes in the OXPHOS system in leaf and root mitochondria of Arabidopsis thaliana subjected to long-term sulphur deficiency
}

\author{
Monika Ostaszewska-Bugajska $^{1} \cdot$ Izabela M. Juszczuk $^{1}$
}

Received: 7 November 2015/Revised: 29 February 2016/Accepted: 2 May 2016/Published online: 14 May 2016

(C) The Author(s) 2016. This article is published with open access at Springerlink.com

\begin{abstract}
Long-term sulphur (S) deficiency in Arabidopsis thaliana affects the functioning of the mitochondrial oxidative phosphorylation system (OXPHOS) via alteration of the multisubunit NADH-ubiquinone oxidoreductase (Complex I; EC 1.6.5.3), which contains several iron-sulphur clusters. Densitometric analysis of bands of respiratory chain complexes after one-dimensional blue-native polyacrylamide gel electrophoresis (BN-PAGE) showed that levels and in-gel capacities of Complex I in leaf and root mitochondria were lower than those of the control. Twodimensional BN/SDS-PAGE showed lower abundance of all Complex I subunits, but the qualitative structural composition (subunit expression and mobility) did not change. In mitochondria of S-deficient $A$. thaliana, impairment of Complex I could be compensated to some extent by additional type II NADH dehydrogenases that do not contain iron-sulphur clusters. The level and capacity of external NADH dehydrogenases in leaf and root mitochondria was higher under $\mathrm{S}$ deficiency, but that of internal NADH dehydrogenases did not differ from the control. The amount of COXII (mitochondrial-encoded subunit of cytochrome $c$ oxidase in Complex IV; EC 1.9.3.1) and the capacity of Complex IV were lower under S deficiency, but levels of alternative oxidase, a bypass to Complex IV, did not change. We discuss $\mathrm{S}$ deficiency in A. thaliana in relation to the assembly and stability of Complex I and to a bypass of Complex I by external type II NADH dehydrogenases.
\end{abstract}

Communicated by E. Schleiff.

Izabela M. Juszczuk

izabelaj@biol.uw.edu.pl

1 Institute of Experimental Plant Biology and Biotechnology, Faculty of Biology, University of Warsaw, Miecznikowa 1, 02-096 Warsaw, Poland
Keywords Additional type II NAD(P)H dehydrogenases . Alternative oxidase · BN-PAGE · Iron-sulphur clusters · Respiratory complexes $\cdot \mathrm{S}$ deficiency

\begin{tabular}{|c|c|}
\hline \multicolumn{2}{|c|}{ Abbreviations } \\
\hline AOX & Alternative oxidase \\
\hline BN-PAGE & $\begin{array}{l}\text { Blue-native polyacrylamide gel } \\
\text { electrophoresis }\end{array}$ \\
\hline BSA & Bovine serum albumin \\
\hline Complex I & NADH-ubiquinone oxidoreductase \\
\hline Complex II & Succinate-ubiquinone oxidoreductase \\
\hline Complex III & Ubiquinol-cytochrome $c$ oxidoreductase \\
\hline Complex IV & Cytochrome $c$ oxidase also referred as COX \\
\hline $\mathrm{I}_{2}+\mathrm{III}_{4}$ & $\begin{array}{l}\text { Supercomplex composed of dimeric } \\
\text { Complex I and two copies of dimeric } \\
\text { Complex III }\end{array}$ \\
\hline $\mathrm{I}+\mathrm{III}_{2}$ & $\begin{array}{l}\text { Supercomplex composed of monomeric } \\
\text { Complex I and dimeric Complex III }\end{array}$ \\
\hline $\mathrm{F}_{1}$ & $F_{1}$ part of the $F_{0} F_{1}$ ATP synthase complex \\
\hline GLDH & L-galactone-1,4-lactone dehydrogenase \\
\hline $\mathrm{ND}_{\text {in }} \mathrm{NADH}$ & Internal NADH dehydrogenase \\
\hline $\mathrm{ND}_{\mathrm{ex}} \mathrm{NADH}$ & External NADH dehydrogenase \\
\hline NDUFS4 & $\begin{array}{l}\text { NADH-ubiquinone oxidoreductase } \mathrm{Fe}-\mathrm{S} \\
\text { protein } 4\end{array}$ \\
\hline OXPHOS & The oxidative phosphorylation system \\
\hline
\end{tabular}

\section{Introduction}

The oxidative phosphorylation system (OXPHOS) in mitochondria consists of five multi-subunit protein complexes (I-V). Four of them (Complexes I-IV) are oxidoreductases that form the respiratory chain. Complex I 
(NADH-ubiquinone oxidoreductase; EC 1.6.5.3), Complex III (ubiquinol-cytochrome $c$ oxidoreductase; EC 1.10.2.2), and Complex IV (cytochrome $c$ oxidase, also referred as COX; EC 1.9.3.1) are transmembrane complexes that transfer electrons within the inner membrane and pump protons from the mitochondrial matrix into the intermembrane space (Schertl and Braun 2014). The backflow of protons into the matrix mediates phosphorylation of ADP to ATP by Complex V ( $\mathrm{F}_{0} \mathrm{~F}_{1}$ ATP synthase; EC 3.6.1.3). A special feature of plant mitochondria is the presence of additional oxidoreductases, internal and external type II $\mathrm{NAD}(\mathrm{P}) \mathrm{H}$ dehydrogenases $\left(\mathrm{ND}_{\mathrm{in} / \mathrm{ex}} \mathrm{NADH}\right)$ and an alternative oxidase (AOX) in the OXPHOS system (Rasmusson et al. 2008; Vanlerberghe 2013). The input site for electrons derived from the oxidation of NADH could be either Complex I or $\mathrm{ND}_{\mathrm{in} / \mathrm{ex}} \mathrm{NADH}$, and oxygen can be reduced to water by either $\mathrm{COX}$ or $\mathrm{AOX}$ at the end of the respiratory chain (Rasmusson et al. 2008).

In the inner mitochondrial membrane, three large oxidative phosphorylation complexes (I, III, and IV) interact to form stable higher structures called supercomplexes (Dudkina et al. 2010). Analysis of the respiratory supercomplexes in the model plant Arabidopsis thaliana by blue-native polyacrylamide gel electrophoresis (BNPAGE) identified three types of supercomplex associations: two copies of Complex I and two copies of dimeric Complex III, $\mathrm{I}_{2}+\mathrm{III}_{4}$; one copy of Complex I and dimeric Complex III, I + $\mathrm{III}_{2}$; and dimeric Complex V, $\mathrm{V}_{2}$ (Eubel et al. 2003). BN-PAGE of potato, spinach, and asparagus mitochondria revealed a low abundance of associations of Complexes I, $\mathrm{III}_{2}$, and IV called 'respirasomes' (Eubel et al. 2004; Krause et al. 2004). BN gels from mitochondria of A. thaliana showed a larger (IVa) and a smaller (IVb) form of Complex IV (Eubel et al. 2003), but the Complex IV-containing supercomplexes were not identified (Dudkina et al. 2006, 2010).

Complex I of A. thaliana is the largest complex of the OXPHOS system (molecular mass of approximately 1 $\mathrm{MDa}$ ), and it consists of mitochondrial and nuclear-encoded subunits (Klodmann and Braun 2011). Three-dimensional gel electrophoresis with mass spectrometry provided a 3D gel map of Arabidopsis Complex I containing 55 types of proteins (Peters et al. 2013). At least 40 of them are homologs of bovine Complex I, nine are unique to plants, and six are extra subunits: three gammatype carbonic anhydrases (CA1-3), two carbonic anhydrase-like proteins (CAL1-2) (Perales et al. 2004, 2005), and L-galactone-1,4-lactone dehydrogenase (GLDH), which is the assembly factor of Complex I (Pineau et al. 2008; Schertl et al. 2012). The L-shaped Complex I is formed by two elongated domains consisting of a membrane arm with an extra spherical domain containing CA1-3 and a peripheral arm that protrudes into the mitochondrial matrix (Dudkina et al. 2006). The peripheral arm can be divided into two functional modules, of which one is the NADH oxidation site at flavin mononucleotide (FMN), and the other is located closer to the membrane arm and is responsible for ubiquinone reduction (Braun et al. 2014).

Nutrient deficiencies are common in plants growing in natural habitats. Recent declines in atmospheric industrial sulphur ( $\mathrm{S})$ emissions as sulphur dioxide $\left(\mathrm{SO}_{2}\right)$ and lower $\mathrm{S}$ supply in mineral fertilisers have led to $\mathrm{S}$ deficiency in soils in many European countries (Vestreng et al. 2007). Most $S$ in plant cells is used in the chloroplasts and mitochondria, which contain proteins that belong to the electron transport chains and include $S$ as a cofactor, mainly conjugated with Fe as Fe-S clusters (Balk and Pilon 2011). Thus, biosynthesis of these clusters requires reduced $\mathrm{S}$ in form of cysteine (Cys) and chelated Fe (Forieri et al. 2013). In the mitochondrial electron transport chain, the major $\mathrm{Fe}-\mathrm{S}$ proteins are Complexes I, II, and III. Complex I contains eight $\mathrm{Fe}-\mathrm{S}$ clusters, two $\left[\mathrm{Fe}_{2} \mathrm{~S}_{2}\right]$ clusters and six $\left[\mathrm{Fe}_{4} \mathrm{~S}_{4}\right]$ clusters, which are essential for electron transduction from $\mathrm{NADH}$ to ubiquinone. All of these $\mathrm{Fe}-\mathrm{S}$ clusters are localised in the subunits of the peripheral arm, and five are in the subunits that form the NADH oxidation site (Couturier et al. 2013). Seven Fe-S clusters pass electrons from NADH oxidised by FMN to the last Fe-S cluster of the peripheral arm and then to ubiquinone (Braun et al. 2014). In addition to electron-transferring $\mathrm{Fe}-\mathrm{S}$ clusters, several subunits of the peripheral and membrane arms of Complex I contain S-rich conserved Cys residues. Thiol moieties $(-\mathrm{SH})$ in these residues are targets of redox regulation of Complex I activity (Braun et al. 2014). Complex II, succinate-ubiquinone oxidoreductase (EC 1.3.5.1), is the smallest constituent of the OXPHOS system, and it does not form supercomplex structures in A. thaliana or other species (Eubel et al. 2003; Sunderhaus et al. 2010; Peters et al. 2012). Three different types of Fe-S clusters contribute to electron transfer in Complex II: $\left[\mathrm{Fe}_{2} \mathrm{~S}_{2}\right],\left[\mathrm{Fe}_{3} \mathrm{~S}_{4}\right]$, and $\left[\mathrm{Fe}_{4} \mathrm{~S}_{4}\right]$ (Couturier et al. 2013). Complex III, a transmembrane multisubunit complex, functions as a homodimer of two identical units (Dudkina et al. 2006), each of which contains one simple $\left[\mathrm{Fe}_{2} \mathrm{~S}_{2}\right]$ cluster in a Rieske subunit (Couturier et al. 2013).

In contrast to Complex I, dimeric Complex III, and Complex IV, all of which are multi-mitochondrial and nuclear gene-encoded transmembrane proteins, additional type II NAD(P)H dehydrogenases and AOX can function as a single type of protein and do not translocate protons (Rasmusson et al. 2008; Millar et al. 2011). Type II internal or external NADH dehydrogenases are encoded by three nuclear gene families in A. thaliana, called NDA (two genes) or $N D C$ (one gene) for internal and $N D B$ (four genes) for external dehydrogenases (Michalecka et al. 
2003). In A. thaliana, AOX is encoded by five nuclear genes: AOX1a-d and AOX2 (Clifton et al. 2006). The 'bypass proteins' do not form parts of any known larger plant mitochondrial supercomplex (Dudkina et al. 2010). AOX becomes a homodimer (Umbach and Siedow 2000), but $\mathrm{ND}_{\text {in/ex }} \mathrm{NADH}$ can exist as monomers (Rasmusson et al. 2004) or form a protein complex with probable heterotrimeric structure (Klodmann and Braun 2011).

Complex I is involved in general symptoms of plant stress responses because it has numerous functions, and its activity can be readily unbalanced by environmental fluctuations (Rasmusson et al. 2008, 2009). Analyses of the respiration in A. thaliana subjected to long-term $\mathrm{S}$ deficiency indicated that Complex I capacity (measured as deamino-NADH oxidation or rotenone-inhibited malate oxidation) was lower than that of plants grown with optimal macronutrient supply (Ostaszewska et al. 2014). Sulphur starvation of Phaseolus vulgaris for 3 weeks also resulted in lower Complex I capacity in leaf and root mitochondria (Juszczuk and Ostaszewska 2011). Under mineral deficiency, plants with lower Complex I capacity show different patterns of up-regulation of $\mathrm{ND}_{\mathrm{in} / \mathrm{ex}} \mathrm{NADH}$. The oxidation of NADH by $\mathrm{ND}_{\text {in }} \mathrm{NADH}$ in mitochondria of S-deficient bean leaves and roots was higher than that in control plants (Juszczuk and Ostaszewska 2011). In contrast, $\mathrm{ND}_{\text {in }} \mathrm{NADH}$ capacity was unchanged but $\mathrm{ND}_{\mathrm{ex}} \mathrm{NADH}$ capacity increased in root mitochondria of Fe-deficient cucumber (Vigani and Zocchi 2010), and in leaf and root mitochondria of S-deficient $A$. thaliana (Ostaszewska et al. 2014). Additional type II ND $\mathrm{N}_{\text {in/ex }} \mathrm{NADH}$ do not contain $\mathrm{Fe}-$ S clusters (Rasmusson et al. 2008), and fewer $S$ atoms are required to maintain their biosynthesis. Under S deficiency, the formation of $\mathrm{Fe}-\mathrm{S}$ clusters is limited, as translation in general, because most $\mathrm{S}$ is intrinsically bound in proteins as Cys and methionine (Met) (Forieri et al. 2013). Posttranslational modification of proteins (including respiratory complexes and additional bypass enzymes), such as protein structure, activity, and stability, depend on the redox status of Cys residues in a reversible reaction of thiol-disulphide interchange (Yi et al. 2010). AOX is a casual mitochondrial protein, the activity of which is dependent on the redox state of the two conserved Cys residues in the catalytic centre. AOX is active when the two Cys residues are reduced as sulphydryl groups, and inactive when they are oxidised to form a disulphide bridge (Crichton et al. 2010). AOX capacity is induced under various stress conditions, including macronutrient limitation (Escobar et al. 2006).

The plant response to sulphur deficiency includes extensive changes at the proteome, metabolome and transcriptome levels (Nikiforova et al. 2004, Sirko et al. 2015). Plant-specific LSU1 and LSU3 (response to Low SUlphur) gene expression was identified as a sulphur deficiency marker because LSU-like proteins are important hubs for integration of signals from environmental stimuli and play a role in the adjustment of plant metabolism to S deficiency at multiple levels (Moniuszko et al. 2013; Sirko et al. 2015).

The aim of this study was to analyse the composition of the OXPHOS system in mitochondria of A. thaliana subjected to long-term $S$ deficiency. Our primary objective was to examine whether leaf and root mitochondria of S-deficient and control plants have the same or different expression profiles and native structure of the respiratory complexes and supercomplexes. Using extended BNPAGE, we performed qualitative and quantitative comparison of the subunits of respiratory chain components, and we examined the correlation between in-gel capacity and protein levels in Complex I under $\mathrm{S}$ deficiency. Complex I, II, III and IV capacity, $\mathrm{ND}_{\mathrm{in} / \mathrm{ex}} \mathrm{NADH}$ capacity and level, AOX level and the transcript abundance of NAD9 and NDUFS4 Complex I subunits and most bypass enzymes were also studied.

\section{Materials and methods}

\section{Plant material and growth conditions}

Arabidopsis thaliana ecotype Columbia-0 plants were grown hydroponically using the Araponics system (Araponics SA, Liège, Belgium) in 1.8-L containers with modified Knop nutrient medium as described in Ostaszewska et al. (2014). The S-deficient plants were grown in nutrient solutions with sulphate salts substituted with the respective chloride salts. Plants were grown for 9 weeks in a growth chamber under $150 \mu \mathrm{mol} \mathrm{m} \mathrm{m}^{-2} \mathrm{~s}^{-1}$ photosynthetically active radiation (daylight and warm white 1:1; LF-40W; Piła, Poland) with a cycle of $8 \mathrm{~h}$ light/16 h dark at $22 / 19^{\circ} \mathrm{C}$, respectively, and $60-70 \%$ relative humidity. Leaves or roots from control or S-deficient plants (Fig. 1) were collected for the assays in the middle of the light period.

\section{Isolation of mitochondria and respiratory measurements}

Washed mitochondria from the leaves or roots were obtained using the method of Keech et al. (2005). Purification of mitochondria was performed as described in Ostaszewska et al. (2014). Respiratory activity of isolated mitochondria was measured using a Clark-type oxygen electrode (Oxygraph and Oxygraph Plus Software, Hansatech, Norfolk, UK). Measurements were performed at $25{ }^{\circ} \mathrm{C}$ in a $0.5 \mathrm{~mL}$ final volume of assay buffer containing $0.45 \mathrm{M}$ mannitol, $10 \mathrm{mM}$ TES (pH 7.5), $10 \mathrm{mM}$

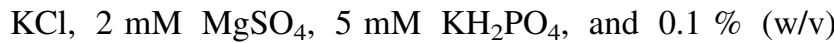




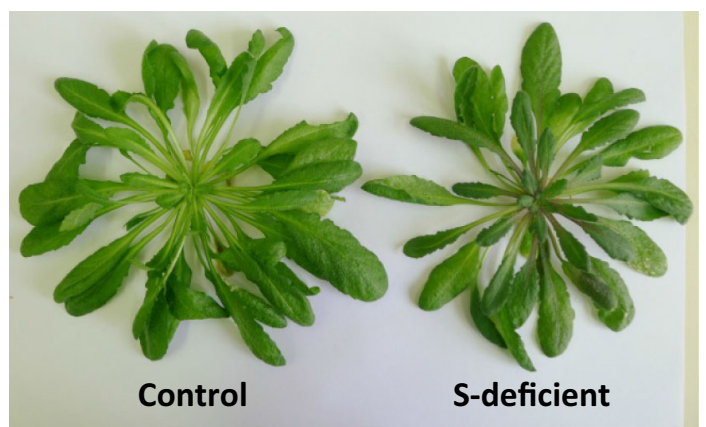

Fig. 1 Arabidopsis thaliana (ecotype Columbia-0) plants cultured hydroponically for 8 weeks in Knop nutrient medium containing $7.5 \mathrm{mM}$ sulphate (control) or without sulphate (S-deficient). S-deficient plants are characterised by lower biomass of the rosette, reduced surface of the leaves, violet pigmentation of the petioles, and chlorotic and necrotic spots on the leaf blades as previously described (Ostaszewska et al. 2014; Ostaszewska-Bugajska et al. 2015)

BSA. Mitochondrial protein $(100 \mu \mathrm{g})$ was added to measure oxygen consumption by $\mathrm{ND}_{\text {in/ex }} \mathrm{NADH}$ with $1 \mathrm{mM}$ $\mathrm{NADH}$ and $1 \mu \mathrm{M} \mathrm{CaCl}{ }_{2}$ in the presence or absence of alamethicin (AlaM, $10 \mu \mathrm{g} \mathrm{ml}^{-1}$ ), a channel-forming peptide that allows the passage of low-molecular weight compounds across the inner mitochondrial membrane to the matrix (Gostimskaya et al. 2003). Complex I was inhibited with $50 \mu \mathrm{M}$ rotenone.

\section{Enzyme spectrophotometric assay}

Complex I, II, III and IV capacities were assayed as described by Vigani et al. (2009), by monitoring the oxidation of NADH at $340 \mathrm{~nm}$ (Complex I), the decrease in concentration of dichloroindophenol at $600 \mathrm{~nm}$ (Complex II), the reduction of cytochrome $c$ at $550 \mathrm{~nm}$ (Complex III) and the oxidation of reduced cytochrome $c$ at $550 \mathrm{~nm}$ (Complex IV). The reactions were followed by the addition of $50 \mu \mathrm{g}$ of mitochondrial protein for leaves and $100 \mu \mathrm{g}$ of protein for roots.

\section{Solubilisation of mitochondrial proteins and BN- PAGE}

After centrifugation of an intact mitochondrial preparation containing $100 \mu \mathrm{g}$ of protein for $20 \mathrm{~min}$ at $20,000 \times \mathrm{g}$, samples were solubilised with digitonin (Cat. No. A1905,0100, AppliChem GmbH, Darmstadt, Germany) in a final concentration of $5 \mathrm{~g}$ per $\mathrm{g}$ of protein by incubation for $20 \mathrm{~min}$ on ice while vortexing every $5 \mathrm{~min}$. Samples were centrifuged at $20,000 \times g$ for $20 \mathrm{~min}$ to remove insoluble material and were supplemented with $7 \mu$ of $5 \%$ (w/v) Coomassie blue G-250 solution in $750 \mathrm{mM}$ aminocaproic acid. Dye-treated protein samples were directly loaded onto a $4 \%$ stacking gel.
One-dimensional BN-PAGE and two-dimensional BN/ SDS-PAGE or BN/BN-PAGE were performed as described by Schägger and Pfeiffer (2001), at $4{ }^{\circ} \mathrm{C}$ and $90-300 \mathrm{~V}$. For BN-PAGE, proteins were separated using a 4-12\% (w/v) acrylamide gradient gel. For BN/BN-PAGE, $n$-dodecyl $\beta$-D-maltoside (DDM) in a final concentration of $0.03 \%(\mathrm{w} / \mathrm{v})$ was used in the cathode buffer for incubation of $\mathrm{BN}$ gel strips. For the second dimension of $\mathrm{BN} / \mathrm{BN}$ PAGE, 5-20\% (w/v) acrylamide gradient gels were used. For BN/SDS-PAGE or BN/BN-PAGE, the gel strips after BN-PAGE were fixed with $1.5 \%$ (w/v) agarose onto the second gel dimension as modified by Eubel et al. (2004). Two-step Tricine-SDS gels [10 and $16 \%(\mathrm{w} / \mathrm{v})$ acrylamide] were used for the second gel dimensions of BN/ SDS-PAGE. The Kaleidoscope Precision Plus Protein Standard (Cat. No. 161-0375, BioRad, Hercules, CA, USA) was used as a marker of molecular weight for proteins. After BN/SDS-PAGE, the gels were stained with silver according to Heukeshoven and Dernick (1986).

\section{Protein and catalytic staining of BN gels}

Protein complexes were visualised by colloidal Coomassie blue staining of the gels according to Neuhoff et al. (1990). The gels were fixed in a solution containing $40 \%(\mathrm{v} / \mathrm{v})$ methanol and $10 \%(\mathrm{v} / \mathrm{v})$ acetic acid for $1 \mathrm{~h}$ and then incubated for $24 \mathrm{~h}$ in the staining solution containing $1.57 \%(\mathrm{w} / \mathrm{v}) \mathrm{H}_{3} \mathrm{PO}_{4}, 7.8 \%$ (w/v) ammonium sulphate, $0.08 \%(\mathrm{w} / \mathrm{v})$ Coomassie Brilliant Blue G-250, and $20 \%$ $(\mathrm{v} / \mathrm{v})$ methanol. Destaining was performed in distilled water for 3 days until the background was clear. Staining for the capacity of Complex I, supercomplex $\mathrm{I}+\mathrm{III}_{2}$, and Complex IV was performed according to Zerbetto et al. (1997) after brief incubation of the gels in the respective reaction buffers.

\section{SDS-PAGE and immunodetection}

Samples of mitochondrial proteins were suspended in loading buffer containing $0.3 \mathrm{M}$ Tris- $\mathrm{HCl}(\mathrm{pH} 6.8), 50 \%$ (v/v) glycerol, $0.02 \%(\mathrm{w} / \mathrm{v})$ bromophenol blue and $5 \%$ (w/v) SDS and were boiled for $5 \mathrm{~min}$. Samples of $20 \mu \mathrm{g}$ (leaf) or $10 \mu \mathrm{g}$ (root) of mitochondrial protein per lane were separated on $10 \%$ SDS-polyacrylamide gels. The SDS and BN/SDS gels were electrotransferred to a nitrocellulose membrane using a Bio-Rad wet blotting apparatus (Bio-Rad). The following primary antibodies were used: rabbit antiserum directed against NAD9 subunit of Complex I from wheat (diluted 1:1000, from J. M. Grinenberger), rabbit polyclonal antisera against GLDH (diluted 1:5000, Cat. No. AS06 182, Agrisera, Vännäs, Sweden) and AOX1/2 (diluted 1:1000, Cat. No. AS04 054, Agrisera), rabbit monoclonal antisera against potato 
external NADH dehydrogenase (anti-NDB1Ct2) or against potato internal NADH dehydrogenase (anti-NDA1) (both diluted 1:1000, from A. Rasmusson, Lund University, Sweden), and anti-NDUFS4 (diluted 1:500, Sigma Aldrich, St. Louis, MO, USA). Anti-rabbit IgG horse radish peroxidase conjugate (Cat. No. 170-6515, Bio-Rad) was used as a secondary antibody at dilutions of 1:10,000 against GLDH and VDAC1, 1:50,000 against AOX1/2 and COXII or 1:20,000 against NDUFS4, NAD9, NDA1 and NDB1Ct2. VDAC1 was used as a loading control. Visualisation was performed with the Immun-Star WesternC chemiluminescent reagent system (Cat. No. 170-5070, BioRad) using Kodak developing reagents (Cat. No. P7042 and P7167, Sigma Aldrich) for X-ray films (Carestream, Kodak, F5388, Sigma Aldrich).

\section{RNA isolation, complementary DNA (cDNA) synthesis, and real-time polymerase chain reaction (qRT-PCR)}

Total RNA was extracted from $100 \mathrm{mg}$ of leaf tissue using the RNeasy Plant Mini kit (Cat. No. 74904, Qiagen, Hilden, Germany). DNase digestion of RNA was performed using the RNase-free DNase Set (Cat. No. 79254, Qiagen). cDNA was synthesised using the RevertAid H Minus Firststrand cDNA synthesis kit (Fermentas, Thermo Fisher Scientific, Waltham, MA, USA). The mRNA levels of mitochondrial electron transport chain bypass genes were quantified using qRT-PCR as described by Escobar et al. (2004). For all qRT-PCR, the iQ SYBR Green Supermix kit was used (Cat. No. 170-8882, Bio-Rad) with primer pairs that were previously described for NDA1 (AT1G07180), NDA2 (AT2G29990), NDB1 (AT4G28220), NDB2 (AT4G05020), NDC1 (AT5G08740) (Michalecka et al. 2003), NDB4 (AT2G20800), AOX1a (AT3G22370), $A O X 1 b$ (AT3G22360), AOX1c (AT3G27620), and $A O X 2$ (Escobar et al. 2004). PP2A (AT1G13320) was used as a reference gene (Czechowski et al. 2005). New primer pairs were designed for the response to low sulphur 1 gene (LSU1; AT3G49580) 5'-ACCGAGGAGGATGCGTGAC$3^{\prime}$ and $5^{\prime}$-AACCGTTCGCTGCCACAA-3', response to low sulphur 3 gene (LSU3; AT3G49570) 5'-GAACGGAG AGTTGGAGAGAGAA- $3^{\prime}$ and 5'-GCCAGTTGCGAGC AGAGTC-3', NADH-ubiquinone oxidoreductase subunit 9 (NAD9; ATMG00070) 5'-GGAGCGAGAAGTTTGGG ATA- ${ }^{\prime}$ and $5^{\prime}$-TGGGTCATCTCAATGGGTTC- ${ }^{\prime}$ and NADH-ubiquinone oxidoreductase $\mathrm{Fe}-\mathrm{S}$ protein 4 (NDUFS4; AT5G67590) 5'-GCATCTTTCTCGCAAG GTGA-3' and 5'-CCAACATTAGCATAGGGGTCA-3'. Control PCRs minus the RT step were run to verify lack of genomic DNA amplification. Transcript abundance was quantified by comparing the values obtained for target genes to those of the reference $P P 2 A$ gene. Relative quantification and qRT-PCR efficiency for the target genes were calculated according to Pfaffl (2001). Transcript levels of genes of S-deficient plants were expressed in relation to control plants, which were given a value of 1 .

\section{Photographic and statistical analysis}

Bands corresponding to the investigated proteins or complexes visible on the gels or X-ray films were scanned. Images were prepared using Adobe Photoshop Elements 8.0. (Adobe Systems, San José, CA, USA). Signal intensities of bands were estimated using Quantity One 4.6.2 software (Bio-Rad) after correcting for background. Results are presented as the mean \pm standard deviation (SD) from at least three independent plant cultures. Experimental data were analysed using Student's $t$ test in Excel 2013 (Microsoft Corporation, Redmond, WA). Differences were considered significant at $P \leq 0.05$.

\section{Results}

\section{Respiratory complexes in leaf and root mitochondria of S-deficient A. thaliana}

To analyse the profile of OXPHOS complexes, mitochondria were isolated from the leaves or roots of $A$. thaliana plants that exhibited symptoms of $\mathrm{S}$ deficiency; in addition to morphological changes (Fig. 1), expression of the LSU1 and LSU3 genes was also increased by 150 and $85 \%$, respectively (Fig. 7). Mitochondrial proteins were resolved by BN-PAGE and visualised by colloidal Coomassie blue staining (Fig. 2a). The use of $5 \mathrm{~g}$ of digitonin per gram of mitochondrial protein enabled identification of single OXPHOS complexes by molecular mass, as previously demonstrated by Eubel et al. (2003) as follows: NADH dehydrogenase (Complex I, $1000 \mathrm{kDa}), \mathrm{F}_{0} \mathrm{~F}_{1}$ ATP synthase (Complex V, $580 \mathrm{kDa}$ ), dimeric cytochrome $c$ reductase (Complex $\mathrm{III}_{2}, 480 \mathrm{kDa}$ ), and cytochrome $c$ oxidase (Complex IV, 300-200 kDa in larger [IVa] and smaller [IVb] isoforms). A heat shock type (HSP) protein complex $(750 \mathrm{kDa})$ was detected above a monomeric form of Complex V. The $F_{1}$ subunit (390 kDa) of the $\mathrm{F}_{0} \mathrm{~F}_{1}$ ATP synthase complex was localised below Complex III. In addition to Complex I, bands of molecular mass $>1500 \mathrm{kDa}$ corresponding to supercomplex $\mathrm{I}+\mathrm{III}_{2}$ were recognisable on BN/SDS (Fig. 3a) gels.

Subsequent BN gels showed more protein bands for leaf mitochondria than for root mitochondria because mitochondrial preparations from leaves always contain a fraction of chloroplast protein contamination. By comparing the gels to BN-PAGE and BN/SDS-PAGE patterns from 

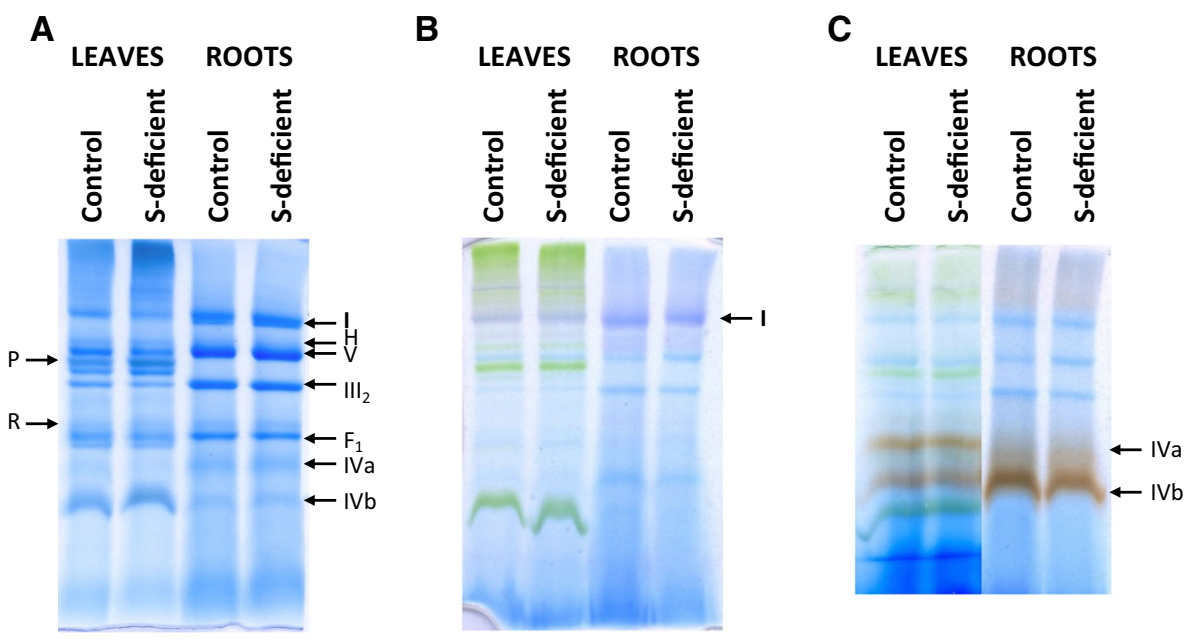

\begin{tabular}{llll} 
D & & & \\
\hline LEAVES & protein & capacity & capacity/protein \\
\hline I & $85^{*} \pm 6$ & $79^{*} \pm 4$ & $0.93^{*}$ \\
IVa & ND & $92 \pm 7$ & - \\
IVb & ND & $91 \pm 7$ & - \\
\hline ROOTS & & & \\
\hline I & $87^{*} \pm 5$ & $81^{*} \pm 4$ & $0.93^{*}$ \\
IVa & ND & $80^{*} \pm 4$ & - \\
IVb & ND & $83^{*} \pm 5$ & - \\
\hline
\end{tabular}

Fig. 2 Analysis of mitochondrial OXPHOS protein complexes by BN-PAGE in leaves and roots of 9-week-old A. thaliana control and S-deficient plants. a Colloidal coomassie blue protein staining. b Complex I. c Complex IV in-gel capacity staining. d Correlation between enzyme capacity and protein level calculated as a percentage of the band density determined for control plants (set to $100 \%$ ). I NADH-ubiquinone oxidoreductase (Complex I); $H$ heat shock protein (HSP) complex; $V \mathrm{~F}_{0} \mathrm{~F}_{1}$ ATP synthase (Complex V); $I I_{2}$, dimeric cytochrome $c$ reductase (Complex III); $F_{1}$ part of the $\mathrm{F}_{0} \mathrm{~F}_{1}$ ATP synthase; $I V a$ and $I V b$ large and small forms of cytochrome $c$ oxidase (Complex IV), respectively. Chloroplast protein

spinach leaf mitochondria presented by Krause et al. (2004), subunits belonging to Photosystem I (PSI) or $\mathrm{CF}_{0} \mathrm{~F}_{1}$ ATP synthase and Rubisco were identified in both types of leaf mitochondria (Figs. 2a, 3a). Most chloroplastic thylakoid and/or stromal proteins were localised close to the $\mathrm{F}_{1}$ subunit (Rubisco) or between monomeric Complex V and dimeric Complex III (PSI subunits). The abundance of these proteins was similar in leaf mitochondria from S-deficient plants and in the control (Figs. 2a, 3a).

\section{Changes in Complex I abundance and capacity}

In mitochondria isolated from leaves and roots of S-deficient $A$. thaliana, the expression and mobility of the respiratory complexes on the BN-PAGE and BN/SDS-PAGE did not differ from those of the control (Fig. 2a). However, contamination was identified by comparing the gels to protein profiles presented by Krause et al. (2004) and is indicated for leaf mitochondria on the left side of the gel: $R$ Rubisco; $P$ Photosystem I subunits. The experiment was repeated four times with a mixture of mitochondria from three independent isolates loaded on the gel (100 $\mu \mathrm{g}$ protein per lane). Representative gels are presented. The gels were scanned and band intensities were estimated as the total volume of optical density after subtraction of the background using Quantity One 4.5.2. software (BioRad). Statistically significant differences $(P<0.05)$ between control and $\mathrm{S}$-deficient plants are indicated by asterisks. ND non-detectable

$\mathrm{S}$ deficiency in $A$. thaliana tissues resulted in quantitative alterations of Complex I in leaf and root mitochondria, consisting of lower levels of total protein (Fig. 2a) and lower abundance of all subunits (Fig. 3a). The abundance of supercomplexes containing Complex I in monomeric or dimeric form, $\mathrm{I}+\mathrm{III}_{2}$ and $\mathrm{I}_{2}+\mathrm{III}_{4}$, was visualised by silver staining after BN/SDS-PAGE and was very low in leaf and root mitochondria of the control but was always lower in tissues from S-deficient plants (Fig. 3a). In-gel staining and densitometric measurements of band intensities after BN-PAGE (Fig. 2b, d) in addition to the spectrophotometric assay (Table 1) showed that the capacity of Complex I in leaf and root mitochondria from S-deficient plants was lower than that of the control. Two-dimensional BN/BN-PAGE confirmed the lower capacity of Complex I and allowed visualisation of the partially degraded 
A
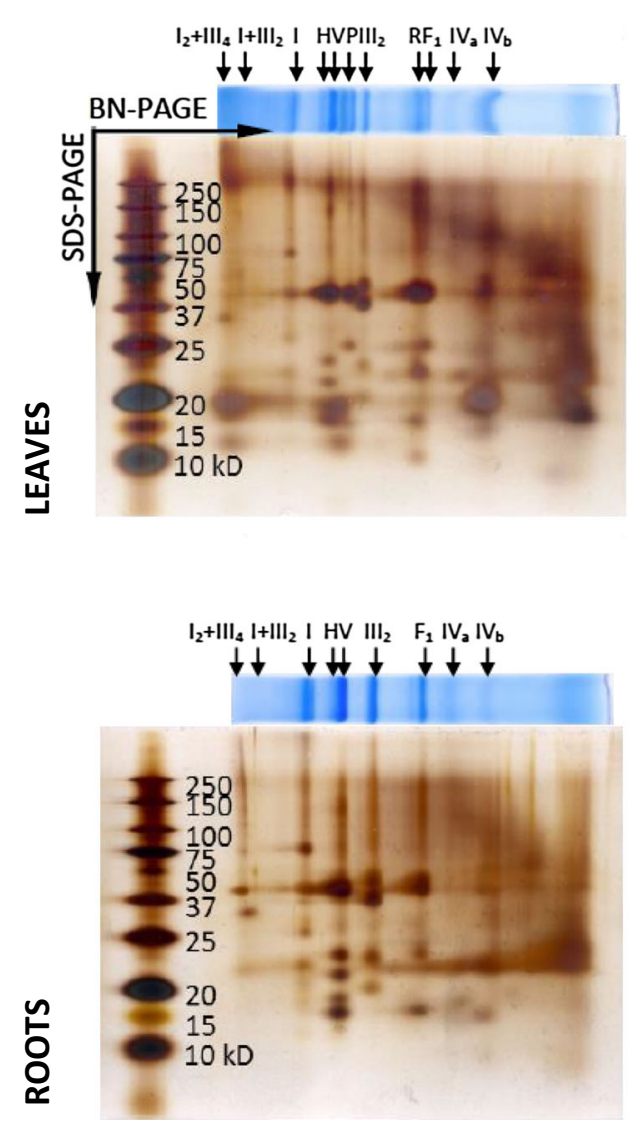

S-deficient
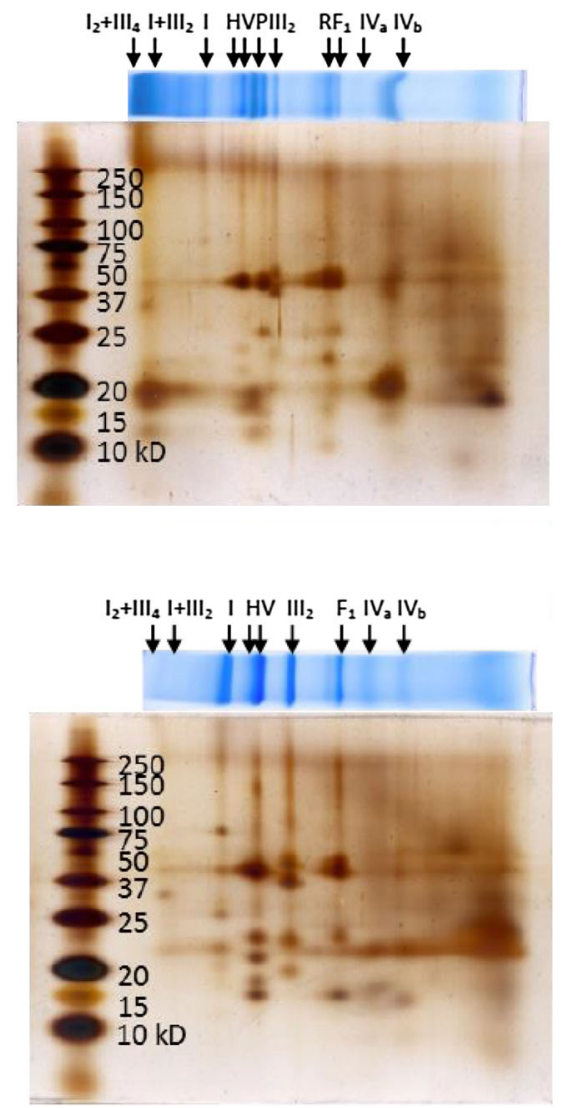

B

\begin{tabular}{lll}
\hline Complex I & LEAVES & ROOTS \\
\hline Protein level & $75^{*} \pm 5$ & $81^{*} \pm 4$ \\
\hline
\end{tabular}

Fig. 3 Identification of OXPHOS complexes and supercomplexes in mitochondria isolated from leaves and roots of 9-week-old A. thaliana control and S-deficient plants. a Two-dimensional resolution of digitonin-solubilised ( $5 \mathrm{~g} \mathrm{~g}^{-1}$ protein) mitochondrial proteins by $\mathrm{BN} /$ SDS-PAGE. The first-dimension BN gels were colloidal Coomassie blue stained (upper panel), and the second-dimension SDS gels were silver-stained (lower panel). Identities of protein complexes are given above the first-dimension gels. The $\mathrm{I}_{2}+\mathrm{III}_{4}$ supercomplex is composed of dimeric Complex I and tetrameric Complex III; the $\mathrm{I}+\mathrm{III}_{2}$ supercomplex is composed of Complex $\mathrm{I}$ and dimeric Complex III. I NADH-ubiquinone oxidoreductase (Complex I); $H$ heat shock protein (HSP) complex; $V \mathrm{~F}_{0} \mathrm{~F}_{1}$ ATP synthase (Complex $\mathrm{V}) ; \mathrm{III}_{2}$ dimeric cytochrome $c$ reductase (Complex III); $F_{1}$ part of the $\mathrm{F}_{0} \mathrm{~F}_{1}$ ATP synthase; $I V a$ and $I V b$ large and small forms of cytochrome

Complex I (Fig. 4c). This degradation could have resulted from several hours required for the BN-PAGE and indicates that Complex I is very susceptible to conditions that include freezing and thawing of mitochondrial preparations (Juszczuk and Rychter 2009). In addition, treatment with the reagents during the experimental procedure disturbs the multiprotein composition. Because of the very low abundance of supercomplexes $\mathrm{I}+\mathrm{III}_{2}$ and $\mathrm{I}_{2}+\mathrm{III}_{4}$ in $c$ oxidase (Complex IV), respectively. Chloroplast protein contamination was identified by comparing the gels to protein profiles presented by Krause et al. (2004) and is indicated for leaf mitochondria on the left side of the gel: $R$ Rubisco; $P$ Photosystem I subunits. b Levels of Complex I subunit calculated as the percentage of all spot densities determined for control plants (set to $100 \%$ ). The experiment was repeated two times with a mixture of mitochondria from three independent isolates loaded on the gel $(100 \mu \mathrm{g}$ protein per lane). Representative gels are presented. The gels were scanned and band intensities were estimated as the total volume of optical density after subtraction of the background, using Quantity One 4.5.2 software (BioRad). Statistically significant differences $(P<0.05)$ between control and S-deficient plants are indicated by asterisks

mitochondria from control and S-deficient A. thaliana, it was not possible to estimate their capacities.

To confirm the influence of S deficiency on the abundance of Fe-S clusters in Complex I, we analysed the level of the nuclear-encoded $18 \mathrm{kDa}$ small $\mathrm{Fe}-\mathrm{S}$ protein, NDUFS4, and mitochondrial-encoded NAD9 subunit by SDS-PAGE and western blotting. The amounts of these two subunits were low in mitochondria from control plants 
Table 1 Enzymatic activities of respiratory chain Complexes I-IV

\begin{tabular}{|c|c|c|c|c|}
\hline \multirow[t]{2}{*}{ Enzymes } & \multicolumn{2}{|l|}{ Leaves } & \multicolumn{2}{|l|}{ Roots } \\
\hline & Control & S-deficient & Control & S-deficient \\
\hline \multicolumn{5}{|c|}{ (U mg ${ }^{-1}$ protein) } \\
\hline Complex I & $2.15^{\mathrm{a}} \pm 0.05$ & $1.53^{\mathrm{b}} \pm 0.04$ & $0.67^{\mathrm{a}} \pm 0.03$ & $0.52^{\mathrm{b}} \pm 0.02$ \\
\hline Complex II & $3.31^{\mathrm{a}} \pm 0.11$ & $2.74^{\mathrm{b}} \pm 0.08$ & $3.00^{\mathrm{a}} \pm 0.12$ & $2.55^{\mathrm{b}} \pm 0.07$ \\
\hline Complex III & $4.32 \pm 0.27$ & $3.98 \pm 0.15$ & $3.50 \pm 0.06$ & $3.46 \pm 0.09$ \\
\hline Complex IV & $3.20^{\mathrm{a}} \pm 0.14$ & $2.73^{\mathrm{b}} \pm 0.11$ & $0.78^{\mathrm{a}} \pm 0.07$ & $0.51^{b} \pm 0.03$ \\
\hline
\end{tabular}

The activities are expressed as non-normalised values in purified mitochondria of leaves or roots of 9-weekold A. thaliana control and S-deficient plants. Values are the mean \pm SD of three biological and four technical replicates. Statistically significant differences $(P<0.05)$ between control and S-deficient plants were determined by Student's $t$ test and are indicated by different superscript letters ${ }^{\mathrm{a}, \mathrm{b}}$ but always lower in S-deficient plants (Fig. 5a, c). The transcripts of the NAD9 and NDUFS4 subunits of Complex I showed decreased levels (approximately 40 and $25 \%$, respectively) in the leaves of S-deficient plants (Fig. 7). Protein levels of nuclear-encoded GLDH, which regulates the assembly of Complex I (Schertl et al. 2012), remained unchanged in the mitochondria of S-deficient A. thaliana relative to the control (Fig. 5b).

To assess whether defects in stability and assembly or catalytic properties affected the capacity of Complex I in mitochondria of S-deficient A. thaliana, we examined the correlation between protein capacity and quantity. Densitometric analysis of the bands showed that the decrease in capacity of Complex I from S-deficient plants was correlated with lower levels of protein: 85 and $87 \%$ of that of the control in leaf and root mitochondria, respectively (Fig. 2d). Quantification of protein bands after BN/SDSPAGE showed even more pronounced changes in the quantity of Complex I subunits (Fig. 3b).

\section{Complex II and Complex III capacity}

We could not obtain good visualisation and compare quantities of Complex II on BN or on BN/SDS gels by colloidal Coomassie blue or silver staining (Figs. 2a, 3a) between S-deficient and control plants. The abundance of Complex III did not differ in S-deficient A. thaliana and control leaf and root mitochondria (Figs. 2a, 3a). The capacities of Complexes II and III were determined by spectrophotometry. The capacity of Complex II was approximately $20 \%$ lower in mitochondria of S-deficient A. thaliana compared to the control, but the capacity of Complex III did not differ (Table 1).

\section{Additional type II NADH dehydrogenases}

One-dimensional BN-PAGE showed that the capacity of $\mathrm{ND}_{\text {in/ex }} \mathrm{NADH}$ was higher in leaf and root mitochondria of S-deficient A. thaliana than in the control (Fig. 4a). After
BN/BN-PAGE, two spots were detectable by in-gel staining for NADH dehydrogenase capacity. One spot at the upper part of the gel represented Complex I activity. The signal in the low-molecular mass range of the gel revealed the capacity of $\mathrm{ND}_{\mathrm{in} / \mathrm{ex}} \mathrm{NADH}$ (Fig. $4 \mathrm{c}$ ). Because $\mathrm{ND}_{\mathrm{in}}$ $\mathrm{NADH}$ and $\mathrm{ND}_{\mathrm{ex}} \mathrm{NADH}$ have similar molecular mass, they cannot be distinguished on $\mathrm{BN}$ or BN/BN gels; therefore, specific antibodies were used and western blotting was performed after BN-PAGE. The level of $\mathrm{ND}_{\mathrm{ex}} \mathrm{NADH}$ was higher in leaf and root mitochondria of S-deficient $A$. thaliana compared to the control, whereas the $\mathrm{ND}_{\mathrm{in}} \mathrm{NADH}$ level did not change (Fig. 4b). We also measured respiration with NADH in the presence or absence of the channelforming peptide AlaM to distinguish between $\mathrm{ND}_{\text {in }} \mathrm{NADH}$ and $\mathrm{ND}_{\mathrm{ex}} \mathrm{NADH}$ capacity. In the mitochondrial preparation separated on the $\mathrm{BN}$ and $\mathrm{BN} / \mathrm{BN}$ gels, we observed a higher capacity for $\mathrm{ND}_{\mathrm{ex}} \mathrm{NADH}$ and no difference for $\mathrm{ND}_{\text {in }} \mathrm{NADH}$ relative to the control (Fig. 3d). This observation was in agreement with our earlier independent polarographic measurements (Ostaszewska et al. 2014).

The transcript levels of several genes encoding additional components (AOX and $\mathrm{ND}_{\mathrm{in} / \mathrm{ex}} \mathrm{NADH}$ ) of the mitochondrial electron transport chain were examined, including three genes encoding $\mathrm{ND}_{\text {in }} \mathrm{NADH}$ (NDAl, $N D A 2$, and $N D C 1$ ), three encoding $\mathrm{ND}_{\text {ex }} \mathrm{NADH}$ ( $N D B 1$, $N D B 2$, and NDB4) and four encoding isoforms of AOX (AOX1a-c and AOX2). Only two genes, NDA2 and AOX1b, showed increased expression (approximately 50 and $30 \%$, respectively) in the leaves of S-deficient plants compared to the control (Fig. 7).

\section{Terminal oxidases of the respiratory chain}

Coomassie blue and silver staining for total protein were insufficient for scanning and quantification of Complex IVa and $\mathrm{IVb}$ isoforms (Figs. 2a, 3a). One-dimensional BNPAGE is not suitable for precise resolution and molecular mass determination of proteins sized less than $300 \mathrm{kDa}$ because of high background and loss of band sharpness; 
A

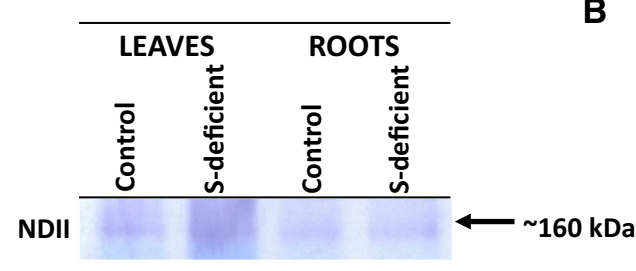

B

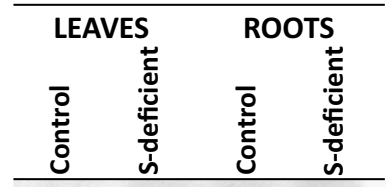

\section{-}

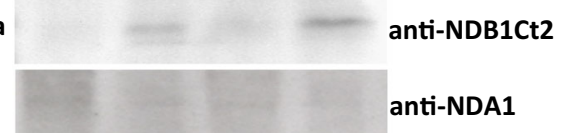

C
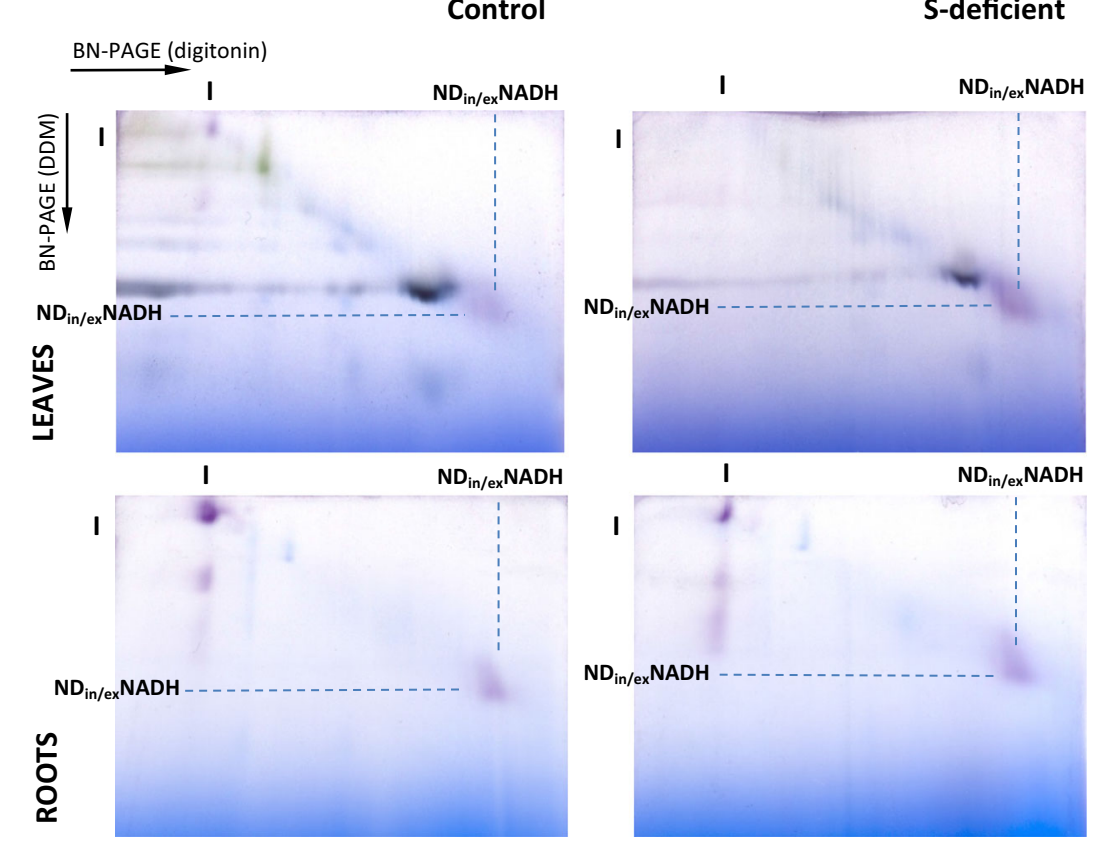

D

\begin{tabular}{lcccc}
\hline & \multicolumn{3}{c}{ LEAVES } & ROOTS \\
\cline { 2 - 5 } & Control & S-deficient & Control & S-deficient \\
\hline Oxygen consumption (nmol $\mathrm{O}_{2}$ min $^{-1} \mathrm{mg}^{-1}$ protein) & & & \\
$\mathrm{ND}_{\text {ex }} \mathrm{NADH}$ plus $\mathrm{ND}_{\text {in }} \mathrm{NADH}$ (+ AlaM) & $67^{\mathrm{b}} \pm 11$ & $77^{\mathrm{a}} \pm 9$ & $51^{\mathrm{b}} \pm 5$ & $57^{\mathrm{a}} \pm 5$ \\
$\mathrm{ND}_{\text {ex }} \mathrm{NADH}$ (- AlaM) & $42^{\mathrm{b}} \pm 2$ & $55^{\mathrm{a}} \pm 5$ & $31^{\mathrm{b}} \pm 3$ & $37^{\mathrm{a}} \pm 4$ \\
$\mathrm{ND}$ in $\mathrm{NADH}$ & 25 & 22 & 20 & 20 \\
\hline
\end{tabular}

Fig. 4 Coomassie blue and in-gel staining for NADH dehydrogenase capacity. a One-dimensional BN-PAGE. b Western blotting of additional type II NADH dehydrogenases with monoclonal antisera against specific subunits of potato external and internal NADH dehydrogenases, anti-NDB1Ct2 against NDB1 protein of external $\mathrm{NADH}$ dehydrogenase and anti-NDA1 against NDA1 protein of internal NADH dehydrogenase. $\mathbf{c}$ Two-dimensional BN/BN-PAGE of respiratory complexes from leaves and roots of 9-week-old $A$. thaliana control and S-deficient plants. Complex I (I) and additional type II internal and external $\mathrm{NADH}$ dehydrogenase $\left(\mathrm{ND}_{\mathrm{in} / \mathrm{ex}} \mathrm{NADH}\right)$ capacities are visualised in violet. First-dimension resolution after digitonin $\left(5 \mathrm{~g} \mathrm{~g}^{-1}\right)$ and second-dimension resolution after treatment with $n$-dodecyl $\beta$-D-maltoside (DDM, $0.05 \%$ ). Gel gradient 5-20\%.
Two-dimensional BN/BN-PAGE was repeated twice. Representative gels/blots are presented. d Oxidation of NADH by mitochondria from leaves and roots of $A$. thaliana (the same mitochondria prepared for protein separation by $\mathrm{BN}$ or BN/BN-PAGE). Substrate concentration was $1 \mathrm{mM} \mathrm{NADH}$ in the presence of $1 \mu \mathrm{M} \mathrm{CaCl}$. Alamethicin (AlaM, $10 \mu \mathrm{g} \mathrm{ml}^{-1}$ ) was used to permeabilize the inner mitochondrial membrane and $50 \mu \mathrm{M}$ rotenone was used to inhibit Complex I. Values are the mean \pm SD from three independent mitochondrial isolates. Statistically significant differences $(P<0.05)$ between control and S-deficient plants were determined by Student's $t$ test and are indicated by different superscript letters ${ }^{\mathrm{a}, \mathrm{b}}$. $\mathrm{ND}_{\mathrm{in}} \mathrm{NADH}$ capacity was estimated by subtracting the values (+AlaM) and $(-\mathrm{AlaM})$ 


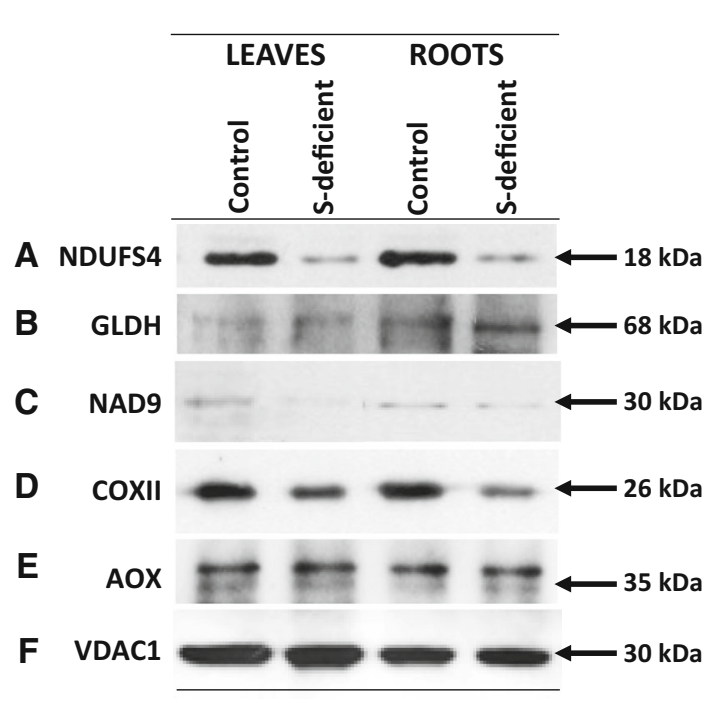

Fig. 5 Western blotting of mitochondrial proteins from leaves and roots of 9-week-old A. thaliana control and S-deficient plants. a NDUFS4 protein (nuclear encoded $\mathrm{Fe}-\mathrm{S}$ subunit of Complex I). b Lgalactone-1,4-lactone dehydrogenase (GLDH), a part of Complex I. c NAD9 (mitochondrial-encoded subunit of Complex I). d COXII (mitochondrial-encoded subunit of Complex IV). e AOX (two bands of AOX). f VDAC1 (porin ion channel located on the outer mitochondrial membrane). Mitochondrial protein $(10 \mu \mathrm{g}$ with the only exception for VDAC1, $20 \mu \mathrm{g}$ from leaf and $10 \mu \mathrm{g}$ from root tissue) was used to indicate the same quantity of mitochondrial protein loaded to the gel. The experiment was repeated five times with a mixture of mitochondria from three independent isolates. Representative gels are presented

thus, we only estimated the capacity of Complex IV isoforms. Comparing leaf and root mitochondrial OXPHOS resolution, it was apparent without densitometric quantification that the quantity of Complex IVa and IVb differs between leaf and root mitochondria (Fig. 2a). Complex IVa capacity was higher in leaf mitochondria than in root mitochondria in control and S-deficient plants, whereas Complex IVb capacity showed the opposite pattern (Fig. 2c). Complex IVa and IVb capacities were lower in root mitochondria of S-deficient A. thaliana as compared than in control plants (Fig. 2d). Complex IV activity measured in a spectrophotometric assay was lower both in leaf and root mitochondria of S-deficient A. thaliana as compared to the control (Table 1). There were no 'respirasome' associations containing a few copies of Complex I, dimeric Complex III and Complex IV in mitochondria of control or S-deficient plants (Fig. 2c). To help explain the lower capacity of Complex IV in S-deficient A. thaliana, we performed western blotting of the mitochondrial-encoded COXII subunit, which showed the decrease in its level (Fig. 5d).

We previously found that AOX capacity did not differ between control and S-deficient plants (Ostaszewska et al. 2014). Here, SDS-PAGE indicated that the levels of two $\sim 35 \mathrm{kDa}$ isoforms of AOX were unchanged in mitochondria isolated from S-deficient A. thaliana leaves and roots relative to the control (Fig. 5e). In contrast, after BN/SDS-PAGE and western blotting, AOX was only detectable in its oxidised form with a size of approximately $60 \mathrm{kDa}$ (Fig. 6). In S-deficient A. thaliana AOX was not associated with any of the respiratory complexes.

\section{Discussion}

Sulphur deficiency changed the OXPHOS system abundance and capacity in leaf and root mitochondria of $A$. thaliana, mainly in terms of Complex I (Fig. 2a, b, d). Lower levels of mitochondrial- and nuclear-encoded subunits of Complex I (Fig. 3a, b) indicated that long-term S deficiency limits Complex I biosynthesis. The number of subunits that join to form structural modules and establish a functional Complex $I$ is a major factor determining assembly of this protein in fungi and mammals (Mimaki et al. 2012). A similar modular assembly pathway was proposed for the Complex I membrane arm in A. thaliana (Meyer et al. 2011; Li et al. 2013). A lower level of the FeS-containing NAD9 mitochondrial-encoded subunit of Complex I was found in S-deficient A. thaliana (Fig. 5c), similar to previous findings in cucumber root mitochondria under Fe deficiency (Vigani et al. 2009), and in both species, Complex I was impaired. Arabidopsis mutants in other mitochondrial-encoded subunits, e.g. NAD7 and NAD4, showed dysfunction in Complex I formation (Gutierres et al. 1997; Karpova and Newton 1999). Moreover, studies of several pentatricopeptide repeat protein (PPR) mutants have shown that all mitochondrial-encoded subunits are required for the proper assembly of the respiratory chain complexes (Colas des Francs-Small et al. 2014; Colas des Francs-Small and Small 2014; Hsieh et al. 2015).

The lack of a plant-specific NDUFS4 subunit containing $\mathrm{Fe}-\mathrm{S}$ in A. thaliana ndufs 4 mutant resulted in the absence of respiratory chain Complex I (Meyer et al. 2009). Analysis of mutant lines in A. thaliana supported the role of NDUFS4 in assembly of the membrane arm of Complex I (Meyer et al. 2011). In the present study, the abundance of small nuclear-encoded 18-kDa NDUFS4 protein was lower in leaf and root mitochondria of S-deficient $A$. thaliana (Fig. 5a), but the question is whether in the control plants all NDUFS4 subunits were incorporated into Complex I. It has been shown that in A. thaliana, the subunits of the matrix-facing soluble arm of Complex I turn over at a faster rate compared to the rest of complex, presumably as a result of damage and recycling, whereas the membranous components degrade more slowly (Nelson et al. 2013). The iron-sulphur protein required for NADH dehydrogenase (INDH) was identified as an assembly factor for Complex I in A. thaliana (Wydro et al. 2013). In 
Fig. 6 Immunological detection of alternative oxidase after resolution of mitochondrial fractions of 9-week-old $A$. thaliana control and S-deficient plants by BN/SDS-PAGE.

Molecular masses of the standard proteins are indicated above the gel (native dimension) or to the right (SDS dimension)

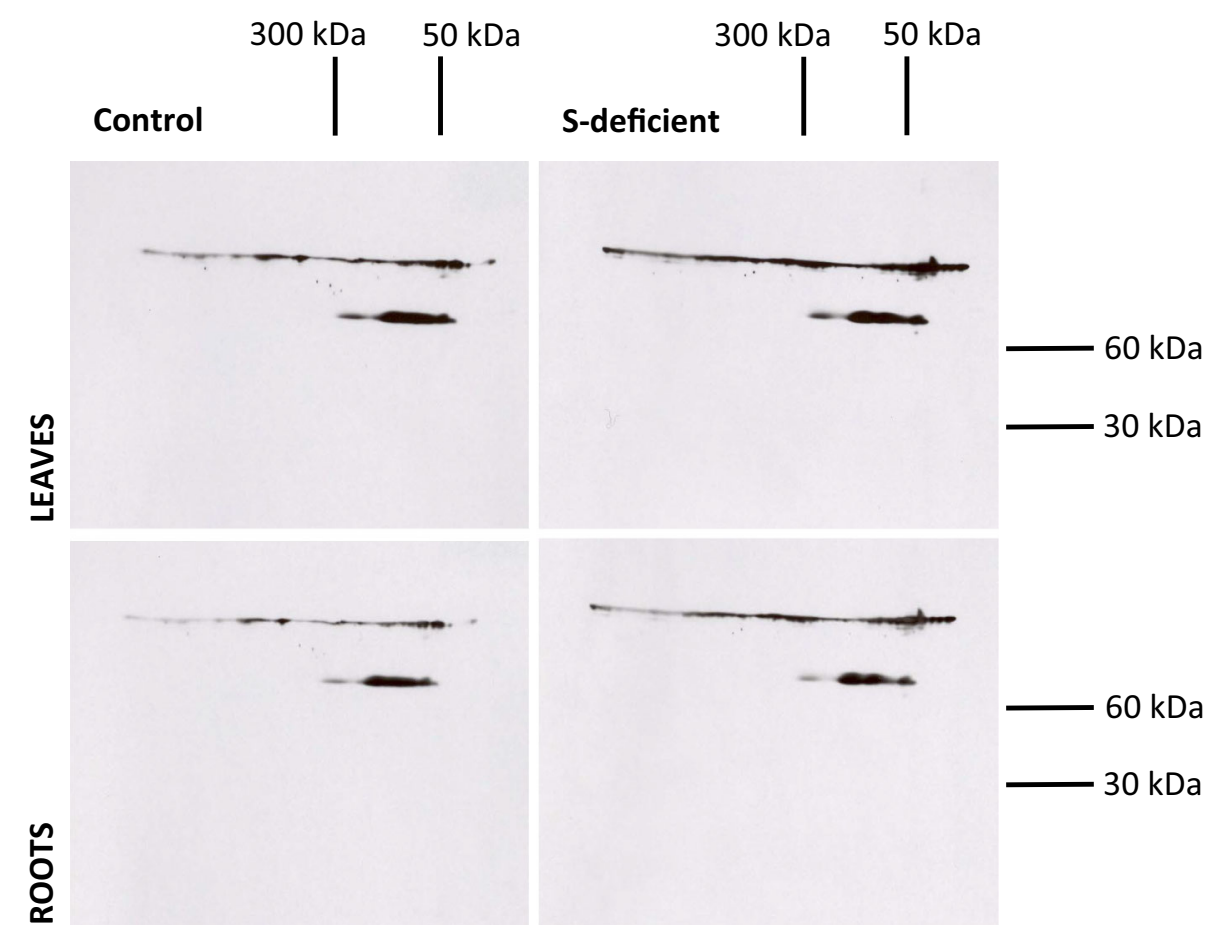

the indh knockout mutant, accumulation of a $650-\mathrm{kD}$ subcomplex was detected, similar to that in Arabidopsis ndufs4 mutants lacking $\mathrm{Fe}-\mathrm{S}$ cluster binding subunits (Meyer et al. 2011). The subunits containing Fe-S clusters are localised in the peripheral arm (Klodmann and Braun 2011); thus, S deficiency in A. thaliana may limit biosynthesis mainly in this part of Complex I.

GLDH is not associated with the holocomplex but with a smaller version of Complex I (Heazlewood et al. 2003), and with three subcomplexes representing Complex I assembly intermediates (Schertl et al. 2012); therefore, it cannot be considered a Complex I subunit (Meyer 2012). However, because the knockout mutant of GLDH does not synthesise Complex I, GLDH has been described as the potential assembly factor for Complex I in A. thaliana (Pineau et al. 2008). Analyses of gldh mutants of $A$. thaliana suggest that GLDH is an assembly factor for the membrane arm of Complex I (Schimmeyer et al. 2016). The similar levels (Fig. 5b) and activities (OstaszewskaBugajska et al. 2015) of GLDH in S-deficient A. thaliana and control plants suggest the maintenance of ascorbate biosynthesis and/or support of Complex I structure when tissue S content decreases. GLDH does not need to be active to function in Complex I assembly (Schertl et al. 2012).

The Complexes II and III were analysed to evaluate whether $\mathrm{S}$ deficiency alters these Fe-S-containing enzymes. The lower capacity of Complex II (Table 1) suggests that its assembly or activity could be strongly dependent on $\mathrm{S}$ availability, similarly to Complex I.
Complex III capacity in S-deficient A. thaliana did not change (Table 1). Because the Rieske $\mathrm{Fe}-\mathrm{S}$ protein is believed to play a role in Complex III dimerization, this prosthetic group must be inserted correctly during Complex III assembly (Hamel et al. 2009). Complex III, always as a dimer, forms supercomplexes with Complex I, and in different species of eukaryotes these associations are conserved because they determine mitochondrial electron transfer (Dudkina et al. 2005, 2010). Thus, under S deficiency, S could be preferentially directed for Complex III biosynthesis, and even a very small amount of $\mathrm{S}$ could be adequate to form the Rieske Fe-S cluster.

Complex IV does not contain $\mathrm{Fe}-\mathrm{S}$ clusters, but its capacity was altered in mitochondria of S-deficient $A$. thaliana (Fig. 2c), consistently with our previous measurements of COX capacity by polarography (Ostaszewska et al. 2014). Levels of the COXII subunit were lower in mitochondria of S-deficient plants (Fig. 5d). The correlation between the mitochondrial-encoded COXII subunit levels and Complex IV capacity suggests that COXII might regulate the assembly or stability of Complex IV. This was previously observed for Complex IV in cucumber MSC16 mitochondria (Juszczuk and Rychter 2009). Building the catalytic centre of the holoenzyme, COXI, COXII and COXIII are the key subunits involved in Complex IV assembly or stability (Meunier and Taanman 2002; Khalimonchuk and Rödel 2005).

The lower levels and/or activities of Complex I, II and IV (Fig. 2a-c; Table 1) may be the result of limited Cys and/or Fe-S clusters. It can be assumed that Cys and Met 
residues comprise $4.92 \%$ of all amino acid residues in the proteins based on the calculation of the random content of these sulphur amino acids encoded by two (Cys, $3.28 \%$ ) or one (Met, $1.64 \%$ ) codons. Bioinformatic analysis of human, bovine, and mouse proteins revealed almost identical $(2.26 \%)$ occurrences of Cys and a correlation between increased complexity of an organism and representation of Cys in the proteins (Miseta and Csutora 2000). Thus, it can be supposed that the sulphur amino acid content in plants is similar to that of mammals. If the average molecular mass of a single amino acid is $110 \mathrm{Da}$, Complex I with a mass of about 1 MDa (Braun et al. 2014) contains 9090 sulphur amino acid residues and 570 atoms of $\mathrm{S}$ in Cys and Met residues. In Complex I, there are eight $\mathrm{Fe}-\mathrm{S}$ clusters, two $\left[\mathrm{Fe}_{2} \mathrm{~S}_{2}\right]$ and six $\left[\mathrm{Fe}_{4} \mathrm{~S}_{4}\right]$ (Couturier et al. 2013), containing 28 atoms of $\mathrm{S}$. This analysis indicated that in S-deficient $A$. thaliana, the additional demand for sulphur for Fe-S centres seems to be negligible but cannot be also excluded.

Much less $\mathrm{S}$ is required to sustain $\mathrm{ND}_{\text {in/ex }} \mathrm{NADH}$ level and/or activity because they do not contain Fe-S clusters and thus could replace the function of Complex $\mathrm{I}$ and maintain NADH oxidation under S deficiency. Parallel BN/ BN-PAGE together with respiratory measurements showed that the $\mathrm{ND}_{\mathrm{ex}} \mathrm{NADH}$ capacity was higher but $\mathrm{ND}_{\text {in }} \mathrm{NADH}$ capacity was unchanged in mitochondria of S-deficient $A$. thaliana (Fig. 4a, c, d). Tobacco CMSII and A. thaliana frostbite1 mitochondrial mutants that lack Complex I, and cucumber MSC16 mutant with lower level of Complex I, display the compensation of Complex I by additional type II NAD(P)H dehydrogenases (Juszczuk et al. 2007; Garmier et al. 2008; Juszczuk and Rychter 2009; Podgórska et al. 2015). The increased capacity of $\mathrm{ND}_{\text {in/ex }} \mathrm{NADH}$ in root mitochondria of S-deficient bean and A. thaliana and in Fe-deficient cucumber may be responsible for rapid adjustment of respiration during prolonged macro- or micronutrient deficiency (Vigani and Zocchi 2010; Juszczuk and Ostaszewska 2011; Ostaszewska et al. 2014). Sulphur deficiency did not affect $\mathrm{ND}_{\mathrm{in} / \mathrm{ex}} \mathrm{NADH}$ localisation in the respiratory chain of $A$. thaliana mitochondria, and $\mathrm{ND}_{\text {in/ex }} \mathrm{NADH}$ do not belong to supercomplexes, as observed for other plant species (Eubel et al. 2003, 2004; Juszczuk and Rychter 2009) including A. thaliana grown under steady-state conditions (Klodmann and Braun 2011).

Alternative oxidase levels did not differ in mitochondria of S-deficient A. thaliana relative to the control (Fig. 5e). The thiol reduction state in the catalytic centre regulates AOX activity (Albury et al. 2009). Sulphur deposition for AOX biosynthesis could be preferentially sustained to maintain the outflow of electrons from ubiquinol and oxidation of the respiratory substrates when COX capacity is affected. Similarly, S deficiency in bean plants does not increase protein levels or AOX capacity, and COX capacity is decreased (Juszczuk and Ostaszewska 2011). Alternative oxidase does not form a part of OXPHOS system in $A$. thaliana under normal conditions (Eubel et al. 2003; Kakizaki et al. 2012). In S-deficient plants, the apparent lack of association of AOX with any of complexes (Fig. 6) confirmed its important role as a simple protein that acts as a bypass for Complexes III and IV. However, i.e., in ripe tomato, when expressed in large amounts, AOX interacts broadly with respiratory chain complexes, whereas when its expression is low, AOX associates specifically with Complex III (Navet et al. 2004).

Sulphur deficiency in A. thaliana modifies the mRNA level of several studied genes. Higher expression of LSU1 and LSU3 (Fig. 7) indicates an adjustment of plant metabolism to $\mathrm{S}$ deficiency. It has been suggested that LSU-like proteins can modulate the degradation of some transcription factors or be involved in regulation of protein degradation system (Sirko et al. 2015). Indeed, the activity of proteases increased in $A$. thaliana under $\mathrm{S}$ deficiency (Ostaszewska-Bugajska et al. 2015). The abundance of transcripts of mitochondrial NAD9 and nuclear NDUFS4 genes encoding Complex I subunits decreased under $\mathrm{S}$ deficiency in A. thaliana. This is in an agreement with the capacity and/or levels of these $\mathrm{Fe}-\mathrm{S}$ containing proteins. The transcripts of two mitochondrial bypass enzymes, NDA2 and AOX1b, encoded by nuclear genes were higher relative to the control (Fig. 7). However, $\mathrm{ND}_{\text {in }} \mathrm{NADH}$ capacity (Fig. 4d; Ostaszewska et al. 2014) and the level of AOX protein remained unchanged (Fig. 5e). Expression of the $A O X 1 b$ gene may play a flower-specific role (Clifton et al. 2006). In S-deficient A. thaliana flowers appeared when plants had fewer leaves compared to the control. Thus, we propose that higher transcript levels of AOX1b protein could reflect earlier programmed flowering. Transcriptomic analysis in response to $\mathrm{S}$ restriction should be integrated with a metabolomic approach because, as in the oilseed rape, most genes are not expressed additively at the protein level (Marmagne et al. 2010). Such differences between the transcription and expression of bypass proteins (Fig. 7) could also occur during the long-term growth of $A$. thaliana under $\mathrm{S}$ deficiency. Temporal differences in transcript and protein level have been described in shortterm growth of S-deficient A. thaliana (Nikiforova et al. 2004), and correlations have been observed between the decrease of mRNA expression and that of protein expression (Higashi et al. 2006). We, therefore, conclude that in S-deficient $A$. thaliana, further levels of transcript-protein correlation regulation exist during protein biosynthesis, some of which could be $\mathrm{S}$ deficiency-specific.

To summarise, we demonstrated that the OXPHOS system in leaf and root mitochondria of S-deficient $A$. thaliana was disturbed, mainly owing to the lower abundance of all Complex I subunits and NAD9 and NDUFS4 


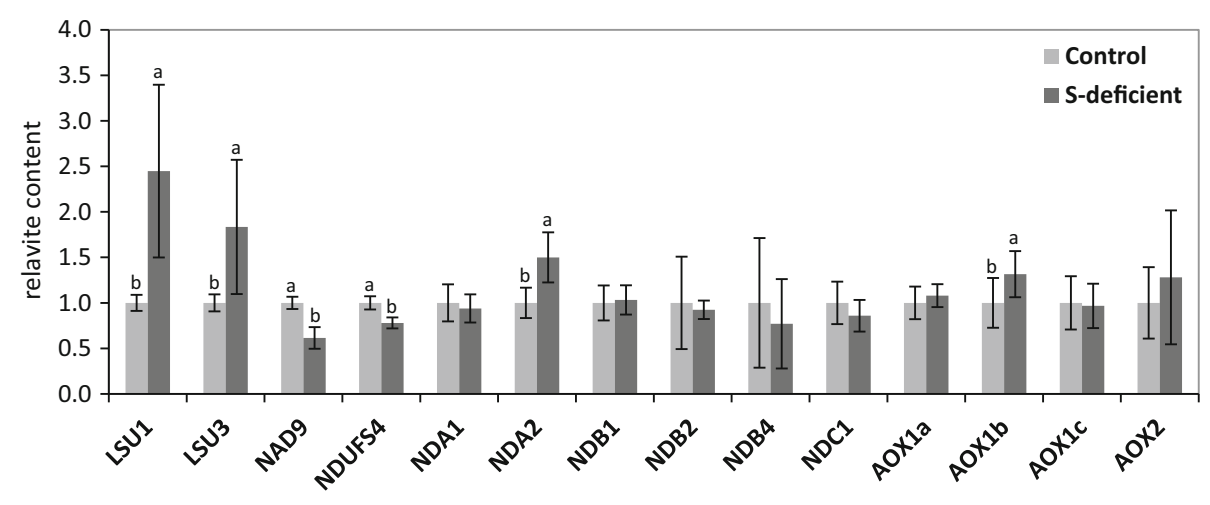

Fig. 7 Transcript levels of the components in the mitochondrial respiratory chain and sulphur responsive genes in the leaves of 9-week-old $A$. thaliana control and S-deficient plants. LSU1 and LSU3, response to low sulphur 1 and 3, NAD9, NADH-ubiquinone oxidoreductase subunit 9, NDUFS4, NADH-ubiquinone oxidoreductase Fe-S protein 4, NDA1, NDA2 and NDC1, type II internal NADH dehydrogenases, NDB1, NDB2 and NDB4, type II external NADH dehydrogenases, AOX1a-c and AOX2,

transcripts. This was correlated with a decrease in total holocomplex content and in-gel capacity. Thus, Complex I could be regulated at both the transcript and protein level of $\mathrm{Fe}-\mathrm{S}$ containing subunits. However, Complex I was not completely blocked; it still contributed to electron inflow for ubiquinone. The impairment of Complex IV capacity also indicated that the outflow of electrons from ubiquinol was altered by $\mathrm{S}$ deficiency. We showed that additional external type II NADH dehydrogenases were induced, leading to bypass of Complex I, and that AOX was maintained to support Complex IV. We hypothesised that the levels of Complex I subunits and/or capacity of Complexes I, II, and IV might be co-ordinately diminished because of the decrease in $\mathrm{S}$ availability for Cys and Fe-S cluster biosynthesis. We found that the OXPHOS system in mitochondria of A. thaliana is remodelled and that mitochondrial plasticity in relation to other cellular processes allows plants to adapt to $\mathrm{S}$ deficiency.

Author contribution statement I.M.J designed, planned, and instructed the research; measured Complex I-IV capacities spectrophotometrically; performed SDS-PAGE and western blotting of COXII, NDA1, NDB1 and NDUFS4; and analysed the data. M.O.B. cultivated the plants, isolated mitochondria; performed extended $\mathrm{BN}$ PAGE experiments, polarographic measurements of oxygen consumption by isolated mitochondria, western blotting analysis of GLDH, AOX1/2, VDAC1 and transcript analyses of respiratory chain enzymes and $L S U 1 / 3$ genes; and analysed the data. I.M.J. and M.O.B. wrote the manuscript. Both authors have read and approved the final version of the manuscript.

Acknowledgments This work was supported by Grant No. N303 800240 to I.M.J. from the National Science Centre (NCN), Poland. isoforms of AOX. The value for each gene is expressed in relation to control plants, which are given a value of 1 . Values are the mean \pm SD of three biological and three technical replicates. Statistically significant differences $(P<0.05)$ between control and S-deficient plants were determined by Student's $t$ test and are indicated by different superscript letters $^{\mathrm{a}, \mathrm{b}}$

Open Access This article is distributed under the terms of the Creative Commons Attribution 4.0 International License (http://crea tivecommons.org/licenses/by/4.0/), which permits unrestricted use, distribution, and reproduction in any medium, provided you give appropriate credit to the original author(s) and the source, provide a link to the Creative Commons license, and indicate if changes were made.

\section{References}

Albury MS, Elliott C, Moore AL (2009) Towards a structural elucidation of the alternative oxidase in plants. Physiol Plant 137:316-327. doi:10.1111/j.1399-3054.2009.01270.x

Balk J, Pilon M (2011) Ancient and essential: the assembly of ironsulfur clusters in plants. Trends Plant Sci 16:218-226. doi:10. 1016/j.tplants.2010.12.006

Braun HP, Binder S, Brennicke A, Eubel H, Fernie AR, Finkemeier I, Klodmann J, König AC, Kühn K, Meyer E, Obata T, Schwarzländer M, Takenaka M, Zehrmann A (2014) The life of plant mitochondrial complex I. Mitochondrion 19:295-313. doi:10.1016/j.mito.2014.02.006

Clifton R, Millar AH, Whelan J (2006) Alternative oxidases in Arabidopsis: a comparative analysis of differential expression in the gene family provides new insights into function of nonphosphorylating bypasses. Biochim Biophys Acta 1757:730-741. doi:10.1016/j.bbabio.2006.03.009

Colas des Francs-Small C, Small I (2014) Surrogate mutants for studying mitochondrially encoded functions. Biochemie 100:234-242. doi:10.1016/j.biochi.2013.08.019

Colas des Francs-Small C, de Longevialle AF, Li Y, Lowe E, Tanz SK, Smith C, Bevan MW, Small I (2014) The pentatricopeptide repeat proteins TANG2 and ORGANELLE TRANSCRIPT PROCESSING439 are involved in the splicing of the multipartite nad5 transcript encoding a subunit of mitochondrial Complex I. Plant Physiol 165:1409-1416. doi:10.1104/pp.114. 244616

Couturier J, Touraine B, Briat JF, Gaymard F, Rouhier N (2013) The iron-sulfur cluster assembly machineries in plants: current knowledge and open questions. Front Plant Sci 4:259. doi:10. 3389/fpls.2013.00259 
Crichton PG, Albury MS, Affourtit C, Moore AL (2010) Mutagenesis of the Sauromatum guttatum alternative oxidase reveals features important for oxygen binding and catalysis. Biochim Biophys Acta 1797:732-737. doi:10.1016/j.bbabio.2009.12.010

Czechowski T, Stitt M, Altmann T, Udvardi MK, Scheible WR (2005) Genome-wide identification and testing of superior reference genes for transcript normalization in Arabidopsis. Plant Physiol 139:5-17. doi:10.1104/pp.105.063743

Dudkina NV, Eubel H, Keegstra W, Boekema EJ, Braun HP (2005) Structure of a mitochondrial supercomplex formed by respiratorychain complexes I and III. Proc Natl Acad Sci USA 102:3225-3229. doi:10.1016/j.bbabio.2009.12.013

Dudkina NV, Heinemeyer J, Sunderhaus S, Boekema EJ, Braun HP (2006) Respiratory chain supercomplexes in the plant mitochondrial membrane. Trends Plant Sci 11:232-240. doi:10.1016/j. tplants.2006.03.007

Dudkina NV, Kouril R, Peters K, Braun HP, Boekema EJ (2010) Structure and function of mitochondrial supercomplexes. Biochim Biophys Acta 1797:664-670. doi:10.1016/j.bbabio. 2009.12.013

Escobar MA, Franklin KA, Svensson AS, Salter MG, Whitelam GC, Rasmusson AG (2004) Light regulation of the Arabidopsis respiratory chain. Multiple discrete photoreceptor responses contribute to induction of type II NAD(P)H dehydrogenase genes. Plant Physiol 136:2710-2721. doi:10.1104/pp.104.046698

Escobar MA, Geisler DA, Rasmusson AG (2006) Reorganization of the alternative pathway of the Arabidopsis respiratory chain by nitrogen supply: opposing effects of ammonium and nitrate. Plant J 45:775-788. doi:10.1111/j.1365-313X.2005.02640.x

Eubel H, Jänsch L, Braun HP (2003) New insights into the respiratory chain of plant mitochondria. Supercomplexes and a unique composition of complex II. Plant Physiol 133:274-286. doi:10. 1104/pp.103.024620

Eubel H, Heinemeyer J, Sunderhaus S, Braun HP (2004) Respiratory chain supercomplexes in plant mitochondria. Plant Physiol Biochem 42:937-942. doi:10.1104/pp.103.024620

Forieri I, Wirtz M, Hell R (2013) Toward new perspectives on the interaction of iron and sulfur metabolism in plants. Front Plant Sci 4:357. doi:10.3389/fpls.2013.00357

Garmier M, Carroll AJ, Delannoy E, Vallet C, Day DA, Small ID, Harvey M (2008) Complex I dysfunction redirects cellular and mitochondrial metabolism in Arabidopsis. Plant Physiol 148:1324-1341. doi:10.1104/pp.108.125880

Gostimskaya IS, Grivennikova VG, Zharova TV, Bakeeva LE, Vinogradov AD (2003) In situ assay of the intramitochondrial enzymes: use of alamethicin for permeabilization of mitochondria. Anal Biochem 313:46-52. doi:10.1016/S00032697(02)00534-1

Gutierres S, Sabar M, Lelandais C, Chetrit P, Diolez P, Degand H, Boutry M, Vedel F, de Kouchkovsky Y, De Paepe R (1997) Lack of mitochondrial and nuclear-encoded subunits of complex I and alteration of the respiratory chain in Nicotiana sylvestris mitochondrial deletion mutants. Proc Natl Acad Sci USA 94:3436-3441

Hamel P, Corvest V, Giegé P, Bonnard G (2009) Biochemical requirements for the maturation of mitochondrial $c$-type cytochromes. Biochim Biophys Acta 1793:125-138. doi:10. 1016/j.bbamcr.2008.06.017

Heazlewood JL, Howell KA, Millar AH (2003) Mitochondrial complex I from Arabidopsis and rice: orthologs of mammalian and fungal components coupled with plant-specific subunits. Biochim Biophys Acta 1604:159-169. doi:10.1016/S00052728(03)00045-8

Heukeshoven J, Dernick R (1986) Silver staining of proteins. In: Radula BJ (ed) Electrophoresis Forum'86. Technische Universität, München, pp 22-27
Higashi Y, Hirai MY, Fujiwara T, Naito S, Noji M, Saito K (2006) Proteomic and transcriptomic analysis of Arabidopsis seeds: molecular evidence for successive processing of seed proteins and its implication in the stress response to sulfur nutrition. Plant J 48:557-571. doi:10.1111/j.1365-313X.2006.02900.x

Hsieh WY, Liao JC, Chang CY, Harrison T, Boucher C, Hsieh MH (2015) The SLOW GROWTH3 pentatricopeptide repeat protein is required for the splicing of mitochondrial NADH dehydrogenase subunit7 intron 2 in Arabidopsis. Plant Physiol 168:490-501. doi:10.1104/pp.15.00354

Juszczuk IM, Ostaszewska M (2011) Respiratory activity, energy and redox status in sulphur-deficient bean plants. Environ Exp Bot 74:245-254. doi:10.1016/j.envexpbot.2011.06.006

Juszczuk IM, Rychter AM (2009) BN-PAGE analysis of the respiratory chain complexes in mitochondria of cucumber MSC16 mutant. Plant Physiol Biochem 47:397-406. doi:10. 1016/j.plaphy.2008.12.022

Juszczuk IM, Flexas J, Szal B, Dąbrowska Z, Ribas-Carbo M, Rychter AM (2007) Effect of mitochondrial genome rearrangement on respiratory activity, photosynthesis, photorespiration and energy status of MSC16 cucumber (Cucumis sativus) mutant. Physiol Plant 131:527-541. doi:10.1111/j.1399-3054.2007.00984.x

Kakizaki Y, Moore AL, Ito K (2012) Different molecular bases underlie the mitochondrial respiratory activity in the homoeothermic spadices of Symplocarpus renifolius and the transiently thermogenic appendices of Arum maculatum. Biochem J 445:237-246. doi:10.1042/BJ20111978

Karpova OV, Newton KJ (1999) A partially assembled complex I in NAD4-deficient mitochondria of maize. Plant J 17:511-521

Keech O, Dizengremel P, Gardeström P (2005) Preparation of leaf mitochondria from Arabidopsis thaliana. Physiol Plant 124:403-409. doi:10.1111/j.1399-3054.2005.00521.x

Khalimonchuk O, Rödel G (2005) Biogenesis of cytochrome $c$ oxidase. Mitochondrion 5:363-388. doi:10.1016/j.mito.2005.08.002

Klodmann J, Braun HP (2011) Proteomic approach to characterize mitochondrial complex I from plants. Phytochemistry 72:1071-1080. doi:10.1016/j.phytochem.2010.11.012

Krause F, Reifschneider NH, Vocke D, Seelert H, Rexroth S, Dencher NA (2004) "Respirasome"-like supercomplexes in green leaf mitochondria of spinach. J Biol Chem 279:48369-48375. doi:10. 1074/jbc.M406085200

Li L, Nelson CJ, Carrie C, Gawryluk RM, Solheim C, Gray MW, Whelan J, Millar AH (2013) Subcomplexes of ancestral respiratory complex I subunits rapidly turn over in vivo as productive assembly intermediates in Arabidopsis. $\mathrm{J}$ Biol Chem 288:5707-5717. doi:10.1074/jbc.M112.432070

Marmagne A, Brabant P, Thiellement H, Alix K (2010) Analysis of gene expression in resynthesized Brassica napus allotetraploids: transcriptional changes do not explain differential protein regulation. New Phytol 186:216-227. doi:10.1111/j.1469-8137. 2009.03139.x

Meunier B, Taanman JW (2002) Mutations of cytochrome $c$ oxidase subunits 1 and 3 in Saccharomyces cerevisiae: assembly defect and compensation. Biochim Biophys Acta 1554:101-107. doi:10.1016/S0005-2728(02)00217-7

Meyer EH (2012) Proteomic investigations of complex I composition: how to define a subunit? Front Plant Sci 3:106. doi:10.3389/fpls. 2012.00106

Meyer EH, Tomaz T, Carroll AJ, Estavillo G, Delannoy E, Tanz SK, Small ID, Pogson BJ, Millar AH (2009) Remodeled respiration in ndufs 4 with low phosphorylation efficiency suppresses Arabidopsis germination and growth and alters control of metabolism at night. Plant Physiol 151:603-619. doi:10.1104/ pp.109.141770

Meyer EH, Solheim C, Tanz SK, Bonnard G, Millar AH (2011) Insights into the composition and assembly of the membrane arm 
of plant complex I through analysis of subcomplexes in Arabidopsis mutant lines. J Biol Chem 286:26081-26092. doi:10.1074/jbc.M110.209601

Michalecka AM, Svensson AS, Johansson FI, Agius SC, Johanson U, Brennicke A, Binder S, Rasmusson AG (2003) Arabidopsis genes encoding mitochondrial type II NAD(P)H dehydrogenases have different evolutionary origin and show distinct responses to light. Plant Physiol 133:642-652. doi:10.1104/pp.103.024208

Millar AH, Whelan J, Soole KL, Day DA (2011) Organization and regulation of mitochondrial respiration in plants. Ann Rev Plant Biol 62:79-104. doi:10.1146/annurev-arplant-042110-103857

Mimaki M, Wang X, McKenzie M, Thorburn DR, Ryan MT (2012) Understanding mitochondrial complex I assembly in health and disease. Biochim Biophys Acta 1817:851-862. doi:10.1016/j. bbabio.2011.08.010

Miseta A, Csutora P (2000) Relationship between the occurrence of cysteine in proteins and the complexity of organisms. Mol Biol Evol 17:1232-1239

Moniuszko G, Skoneczny M, Zientara-Rytter K, Wawrzyńska A, Głów D, Cristescu SM, Harren FJM, Sirko A (2013) Tobacco LSU-like protein couples sulphur-deficiency response with ethylene signalling pathway. J Exp Bot 64:5173-5182. doi:10. 1093/jxb/ert309

Navet R, Jarmuszkiewicz W, Douette P, Sluse-Goffart CM, Sluse FE (2004) Mitochondrial respiratory chain complex patterns from Acanthamoeba castellanii and Lycopersicon esculentum: comparative analysis by BN-PAGE and evidence of protein-protein interaction between alternative oxidase and Complex III. J Bioenerg Biomem 36:471-479

Nelson CJ, Li L, Jacoby RP, Millar AH (2013) Degradation rate of mitochondrial proteins in Arabidopsis thaliana cells. J Proteome Res 12:3449-3459. doi:10.1021/pr400304r

Neuhoff V, Stamm R, Pardowitz I, Arold N, Ehrhardt W, Taube D (1990) Essential problems in quantification of proteins following colloidal staining with coomassie brilliant blue dyes in polyacrylamide gels, and their solution. Electrophoresis 11:101-117

Nikiforova VJ, Gakière B, Kempa S, Adamik M, Willmitzer L, Hesse $\mathrm{H}$, Hoefgen R (2004) Towards dissecting nutrient metabolism in plants: a systems biology case study on sulphur metabolism. J Exp Bot 55:1861-1870. doi:10.1093/jxb/erh177

Ostaszewska M, Juszczuk IM, Kołodziejek I, Rychter AM (2014) Long-term sulphur starvation of Arabidopsis thaliana modifies mitochondrial ultrastructure and activity and changes tissue energy and redox status. J Plant Physiol 171:549-558. doi:10. 1016/j.jplph.2013.12.013

Ostaszewska-Bugajska M, Rychter AM, Juszczuk IM (2015) Antioxidative and proteolytic systems protect mitochondria from oxidative damage in S-deficient Arabidopsis thaliana. J Plant Physiol 186-187:25-38. doi:10.1016/j.jplph.2015.07.011

Perales M, Parisi G, Fornasari MS, Colaneri A, Villarreal F, Gonzalez-Schain N, Echave J, Gomez-Casati D, Braun HP, Araya A, Zabaleta E (2004) Gamma carbonic anhydrase like complex interact with plant mitochondrial complex I. Plant Mol Biol 56:947-957. doi:10.1007/s11103-004-6324-z

Perales M, Eubel H, Heinemeyer J, Colaneri A, Zabaleta E, Braun HP (2005) Disruption of a nuclear gene encoding a mitochondrial gamma carbonic anhydrase reduces complex I and supercomplex $\mathrm{I}+\mathrm{III}_{2}$ levels and alters mitochondrial physiology in Arabidopsis. J Mol Biol 350:263-277. doi:10.1016/j.jmb.2005.04.062

Peters K, Niessen M, Peterhänsel C, Späth B, Hölzle A, Binder S, Marchfelder A, Braun HP (2012) Complex I-complex II ratio strongly differs in various organs of Arabidopsis thaliana. Plant Mol Biol 79:273-284. doi:10.1007/s11103-012-9911-4

Peters K, Belt K, Braun HP (2013) 3D gel map of Arabidopsis complex I. Front Plant Sci 4:153. doi:10.3389/fpls.2013.00153
Pfaffl MW (2001) A new mathematical model for relative quantification in real-time RT-PCR. Nucleic Acids Res 29:e45. doi:10. 1093/nar/29.9.e45

Pineau B, Layoune O, Danon A, De Paepe R (2008) L-galactono-1,4lactone dehydrogenase is required for the accumulation of plant respiratory complex I. J Biol Chem 283:32500-32505. doi:10. 1074/jbc.M805320200

Podgórska A, Ostaszewska M, Gardeström P, Rasmusson AG, Szal B (2015) In comparison with nitrate nutrition, ammonium nutrition increases growth of the frostbite1 Arabidopsis mutant. Plant Cell Environ 38:224-237. doi:10.1111/pce.12404

Rasmusson AG, Soole KL, Elthon TE (2004) Alternative NAD(P)H dehydrogenases of plant mitochondria. Ann Rev Plant Biol 55:23-39. doi:10.1146/annurev.arplant.55.031903.141720

Rasmusson AG, Geisler DA, Møller IM (2008) The multiplicity of dehydrogenases in the electron transport chain of plant mitochondria. Mitochondrion 8:47-60. doi:10.1016/j.mito.2007.10.004

Rasmusson AG, Fernie AR, van Dongen JT (2009) Alternative oxidase: a defence against metabolic fluctuations? Physiol Plant 137:371-382. doi:10.1111/j.1399-3054.2009.01252.x

Schägger H, Pfeiffer K (2001) The ratio of oxidative phosphorylation complexes $\mathrm{I}-\mathrm{V}$ in bovine heart mitochondria and the composition of respiratory chain supercomplexes. J Biol Chem 276:37861-37867. doi:10.1074/jbc.M106474200

Schertl P, Braun HP (2014) Respiratory electron transfer pathways in plant mitochondria. Front Plant Sci 5:163. doi:10.3389/fpls. 2014.00163

Schertl P, Sunderhaus S, Klodmann J, Grozeff GE, Bartoli CG, Braun HP (2012) L-galactono-1,4-lactone dehydrogenase (GLDH) forms part of three subcomplexes of mitochondrial complex I in Arabidopsis thaliana. J Biol Chem 287:14412-14419. doi:10. 1074/jbc.M111.305144

Schimmeyer J, Bock R, Meyer EH (2016) L-Galactono-1,4-lactone dehydrogenase is an assembly factor of the membrane arm of mitochondrial complex I in Arabidopsis. Plant Mol Biol 90:117-126. doi:10.1007/s11103-015-0400-4

Sirko A, Wawrzyńska A, Rodriguez MC, Sęktas P (2015) The family of LSU-like proteins. Front Plant Sci 5:774. doi:10.3389/fpls. 2014.00774

Sunderhaus S, Klodmann J, Lenz C, Braun HP (2010) Supramolecular structure of the OXPHOS system in highly thermogenic tissue of Arum maculatum. Plant Physiol Biochem 48:265-272. doi:10. 1016/j.plaphy.2010.01.010

Umbach AL, Siedow JN (2000) The cyanide-resistant alternative oxidases from the fungi Pichia stipitis and Neurospora crassa are monomeric and lack regulatory features of the plant enzyme. Arch Biochem Biophys 378:234-245. doi:10.1006/abbi.2000.1834

Vanlerberghe GC (2013) Alternative oxidase: a mitochondrial respiratory pathway to maintain metabolic and signaling homeostasis during abiotic and biotic stress in plants. Int $\mathrm{J}$ Mol Sci 14:6805-6847. doi:10.3390/ijms14046805

Vestreng V, Myhre G, Fagerli H, Reis S, Tarrasón L (2007) Twentyfive years of continuous sulphur dioxide emission reduction in Europe. Atmos Chem Phys 7:3663-3681. doi:10.5194/acp-73663-2007

Vigani G, Zocchi G (2010) Effect of Fe deficiency on mitochondrial alternative $\mathrm{NAD}(\mathrm{P}) \mathrm{H}$ dehydrogenases in cucumber roots. J Plant Physiol 167:666-669. doi:10.1111/j.1469-8137.2008.02747.x

Vigani G, Maffi D, Zocchi G (2009) Iron availability affects the function of mitochondria in cucumber roots. New Phytol 182:127-136. doi:10.1111/j.1469-8137.2008.02747.x

Wydro MM, Sharma P, Foster JM, Bych K, Meyer EH, Balk J (2013) The evolutionarily conserved iron-sulfur protein INDH is required for Complex I assembly and mitochondrial translation in Arabidopsis. Plant Cell 25:4014-4027. doi:10.1105/tpc.113.117283 
Yi H, Galant A, Ravilious GE, Preuss ML, Jez JM (2010) Sensing sulphur conditions: simple to complex protein regulatory mechanisms in plant thiol metabolism. Mol Plant 3:269-279. doi:10. 1093/mp/ssp112
Zerbetto E, Vergani L, Dabbeni-Sala F (1997) Quantification of muscle mitochondrial oxidative phosphorylation enzymes via histochemical staining of blue native polyacrylamide gels. Electrophoresis 18:2059-2064. doi:10.1002/elps.1150181131 